\title{
Collective Problem-Solving: The Role of Self- Efficacy, Skill, and Prior Knowledge
}

\author{
Dorit Geifman and Daphne R. Raban \\ Faculty of Management and the Center for Internet Research, \\ University of Haifa, Haifa, Israel
}

\section{dgeifman@univ.haifa.ac.il draban@univ.haifa.ac.il}

\begin{abstract}
Self-efficacy is essential to learning but what happens when learning is done as a result of a collective process? What is the role of individual self-efficacy in collective problem solving? This research examines the manifestation of self-efficacy in prediction markets that are configured as collective problem-solving platforms and whether self-efficacy of traders affects the collective outcome.

Prediction markets are collective-intelligence platforms that use a financial markets mechanism to combine knowledge and opinions of a group of people. Traders express their opinions or knowledge by buying and selling "stocks" related to questions or events. The collective outcome is derived from the final price of the stocks.

Self-efficacy, one's belief in his or her ability to act in a manner that leads to success, is known to affect personal performance in many domains. To date, its manifestation in computer-mediated collaborative environments and its effect on the collective outcome has not been studied.

In a controlled experiment, 632 participants in 47 markets traded a solution to a complex problem, a naïve framing of the knapsack problem. Contrary to earlier research, we find that technical and functional self-efficacy perceptions are indistinguishable, probably due to a focus on outcomes rather than on resources. Further, results demonstrate that prediction markets are an effective collective problem-solving platform that correctly aggregates individual knowledge and is resilient to traders' self-efficacy.
\end{abstract}

Keywords: collective problem-solving, self-efficacy, prediction markets, social influence.

Material published as part of this publication, either on-line or in print, is copyrighted by the Informing Science Institute. Permission to make digital or paper copy of part or all of these works for personal or classroom use is granted without fee provided that the copies are not made or distributed for profit or commercial advantage AND that copies 1) bear this notice in full and 2) give the full citation on the first page. It is permissible to abstract these works so long as credit is given. To copy in all other cases or to republish or to post on a server or to redistribute to lists requires specific permission and payment of a fee. Contact Publisher@InformingScience.org to request redistribution permission.

\section{Introduction}

Collective problem-solving is a process whereby individuals are tasked with solving a problem and the sum total of the individual solutions yields a collective solution. Summation is done by a variety of online platforms which aggregate individual knowledge, decisions, and creativity into a pooled intelligence

Editor: Janice Whatley

An earlier, shorter version of this paper was presented at the Chais conference 2015, in Raanana, Israel, and included in Y. Eshet-Alkalai, I. Blau, A. Caspi, N. Geri, Y. Kalman, \& V. Silber-Varod (Eds.), Proceedings of the 10th Chais Conference for the Study of Innovation and Learning Technologies 2015: Learning in the Technological Era. Raanana: The Open University of Israel. 
artifact. Prediction markets are a genre of collective-intelligence platforms used for problem solving. They use financial markets as an underlying mechanism to aggregate dispersed information, predict future events, and combine knowledge and opinions of a large and distributed group of people. In such markets, stocks represent a statement to be evaluated or an event to be predicted. The price of the stocks traded reflects the market's opinion as to the probability of the occurrence of the event or the correctness of the statement. Price also serves as a signal for traders and as such provides a learning opportunity for improvement of the individual solutions. Prediction markets are deployed as public platforms on the Web as well as within organizations.

Self-efficacy, the belief in one's own ability to act in a manner that leads to success, affects individual performance by determining goal selection, course of action, and persistence (Bandura, 1997). There is a general consensus among researchers that self-efficacy is not a general trait but a disposition that is linked to the specific task and the circumstances in which it takes place (Bandura, 2012). People who use computers to perform knowledge work engage simultaneously in two tasks. The first is coping with the technical aspects of operating the computer application used for the task and the other is the intellectual task itself. Previous studies addressed the interplay of perception dimensions of self-efficacy at such complex tasks (Looney, Valacich, Todd, \& Morris, 2006; Marakas, Yi, \& Johnson, 1998) and other studies demonstrated that individuals who exhibit higher degrees of self-efficacy perform better at problem solving (Bandura \& Wood, 1989; Bouffard-Bouchard, 1990; Pajares \& Kranzler, 1995).

In prediction markets, there is a high degree of integration between the technical and functional perspectives of the trading task, as traders need to interpret market price and implement trading decisions accordingly. The first objective of this research is to study the interplay of the technical and functional perspectives of trading on traders' self-efficacy.

Opinions on the effect of behavioral biases on the outcome of prediction markets differ. Some scholars claim that prediction markets are resilient to behavioral and cognitive biases (Forsythe, Rietz, \& Ross, 1999), while others claim that biases affect market accuracy (Cowgill, Wolfers, \& Zitzewitz, 2008; Gjerstad \& Hall, 2005). This research investigates the effect of self-efficacy on problem-solving in prediction markets.

This paper presents a controlled experiment examining the effectiveness of prediction markets as a collective problem-solving platform and the effect of traders' self-efficacy on the market resilience. It starts with a review of literature on individual and collective problem solving followed by the theory of self-efficacy and its relevance to problem-solving, paying special attention to the measurement of self-efficacy at complex tasks. The paper then describes collaborative platforms that are used for collective problem solving delving into a specific family of such platforms, prediction markets. Next, we report the experimental research method, the results and their discussion, and a summary of the findings.

\section{Problem-Solving}

Intellectual challenges come in various forms that involve different kinds of cognitive tasks, solving strategies, and heuristics. Problems lie on a spectrum that spans between well-structured problems that converge into a conclusive deterministic solution and ill-structured problems that are set in vague and ambiguous context, are not subject to a deterministic solution, and involve uncertainty in the problem domain and the solution space. Stasser and Dietz-Uhler (2001) devised a two-dimensional classification to distinguish the cognitive abilities that people employ to cope with diverse intellectual challenges. The first dimension comes from the decision-making domain and relates to the structural characteristic of the problem, the response format. It distinguishes between selection from several options and rating, i.e., identifying a solution along a continuum (Payne, 1982). The second dimension of the classification is the demonstrability of the solution 
which distinguishes between intellective tasks that deal with problems for which there exists a demonstrable correct solution and judgmental tasks that are evaluative and do not result in an objective outcome (Laughlin \& Ellis, 1986). The classification renders four categories of cognitive tasks: choice, judgment, problem-solving, and estimation (Table 1). This paper focusses on the category of problem solving tasks.

Table 1: Cognitive task classification (Stasser \& Dietz-Uhler, 2001)

\begin{tabular}{llll}
\hline & \multicolumn{2}{c}{ Response format } \\
\cline { 3 - 4 } & & Select & Rate \\
\hline \multirow{2}{*}{ Demonstrability } & Judgmental & Choice & Judgment \\
& Intellective & $\begin{array}{l}\text { Problem- } \\
\text { solving }\end{array}$ & Estimation \\
\hline
\end{tabular}

It is not surprising that information processing models are dominant theories of problem-solving in the field of cognitive psychology. Research into cognitive models that explain the process of problem solving gained momentum with the introduction of computers, notably with the important work of Herbert Simon, a pioneering scholar in the fields of artificial intelligence and cognitive psychology. By modeling complex systems as Artificial Worlds, Simon (1969) created the basis for a theoretical framework of problem solving that consists of two associated subprocesses: understanding the problem and search processes. His cognitive models were implemented as computer simulation, the General Problem Solver (GPS), and established the symbiotic relationships between the disciplines of cognitive psychology and artificial intelligence (Newell $\&$ Simon, 1972). The terminology used by the two disciplines and their respective theories and models may differ, but in essence both identify three components: givens, goals, and operations that are associated with a certain problem space. The givens are the information and resources available for the task. The goals are the desired outcomes of the process, and the operations are the rules and actions that are applied on the givens to achieve the goals (Janssen, 1997; Wang \& Chiew, 2010).

In general, problem-solving approaches follow one of two strategies: an iterative strategy or decomposition and synthesis. The selection of a strategy mainly depends on how readily the solving task can be divided into sub-tasks. In the iterative strategy, the problem solver gradually approaches the final solution in incremental or iterative steps. In decomposition and synthesis strategy, the problem is decomposed into sub-problems and the solutions to the sub-problems are then synthesized into a combined, final solution.

The similarity between the cognitive psychology and artificial intelligence continues when we move from individual problem solving to collective or distributed problem-solving, where several agents, human or computerized, collaborate on the task. In both domains, scholars and practitioners believe that cooperation among multiple actors in solving a problem will improve the efficiency of the process. This led, on one hand, to the development of cooperative and distributed systems, where automatic agents cooperate in solving a problem, and on the other hand, to group problem-solving, where teams of individuals work together to reach a collective decision or solution. While the motivation of computerized distributed problem solving mechanisms was mainly to improve the efficiency of the "operation" component of the problem-solving process, members of problem-solving teams were expected to extend the scope of the information inputs, the "givens", as well as the diversity in solving strategies and heuristics. 
The effectiveness of groups in collective problem-solving and decision-making is debated. Some studies suggested that, in many cases, the outcome of collective decision methods outperforms individual judgment (Brown, 2000; Stasser \& Dietz-Uhler, 2001). However, deficiencies, be they theoretical or practical, were identified in most types of group processes. Previous studies identified informational influence and polarization in small deliberation groups (Burnstein \& Vinokur, 1977; Gigone \& Hastie, 1993; Isenberg, 1986; Stasser \& Titus, 1985) and the Groupthink phenomenon demonstrated the normative social influence, which may prevail in group processes (Janis, 1982). The current study focuses on the effect of individual differences on collective problem-solving.

\section{Self-Efficacy}

Self-efficacy is one's beliefs in one's capabilities to organize and execute the courses of action required to produce given attainments. According to the self-efficacy theory, pioneered by Albert Bandura (1977), self-efficacy determines goal selection, the initiation of coping behavior and effort, persistence in the face of obstacles, and, consequently, affects task performance. The theory suggests that cognitive, social and affective processes, which differ among individuals, play an important role in the acquisition, regulation, and retention of behavior patterns. These processes, combined with environmental stimuli and reinforcements, may strengthen or weaken effective behavior.

Bandura identifies four informational cues that influence self-efficacy: enactive mastery, vicarious experience, verbal persuasion, and emotional arousal. Enactive mastery means that a successful accomplishment feeds back into one's efficacy expectations as reinforcement. It is the most influential source of self-efficacy as it raises mastery expectation and decreases fear and other inhibiting feelings. Vicarious experience is the symbolic modeling of the right behavior by looking at others performing a task. The efficacy expectations induced from vicarious experience are likely to be weaker than those arising from own accomplishments, as they do not present an authentic experiential basis. A third factor, verbal persuasion, i.e., leading a person through suggestion into believing that he or she can cope successfully with a task, was also found to have a lesser effect on efficacy expectations than enactive mastery. Lastly, stressful situations and fear reactions, or positive mood, generate emotional arousal that may greatly influence efficacy expectations (Bandura, 1997).

A large body of research established that self-efficacy shapes the effective performance of individuals in a wide variety of areas such as learning and academic achievements (Bandura \& Schunk, 1981; Chemers, Hu, \& Garcia, 2001), organizational behavior (Bandura \& Wood, 1989; Krueger \& Dickson, 1994), coping with health conditions (Condiotte \& Lichtenstein, 1981; O’Leary, 1985), attaining goals (Bandura \& Wood, 1989; Locke, Frederick, Lee, \& Bobko, 1984) and more.

In tasks that rely on cognitive skills, self-efficacy beliefs affect cognitive states of the individual as well as his or her thinking processes. When looking into the achievements of a large cohort of 15-year old students in the Programme of International Student Assessment (PISA), Parker, Marsh, Ciarrochi, Marshall, and Abduljabbar (2014) found a significant relationship between math self-efficacy and math achievements. Bouffard-Bouchard (1990) demonstrated that differences in efficacy perceptions were related to the number of problems completed, the efficiency of problem-solving strategies, and the accuracy of self-evaluation of responses. People with high personal efficacy focused their attention on analyzing and finding solutions to problems in contrast to people with lower efficacy, who were beset with doubts, tended to turn their attention inwardly, and became self-occupied (Bandura \& Wood, 1989). People who perceived themselves more efficacious at the task were quicker to dispose of faulty thinking directions and are less inclined to reject good solutions prematurely (Bouffard-Bouchard, Parent, \& Larivee, 1991). 


\section{Measuring Self-Efficacy}

Self-efficacy varies across activities and circumstances; therefore, Bandura (1977) suggested that it is not a global disposition and that its estimate is strongest and most accurate when determined by domain-linked measures. To fully capture the richness and the subtleties of the self-efficacy agency, its measurement should reflect the composition of the task and relate to its different modalities. Bandura (1986) recommends using multidimensional constructs to capture the richness of efficacy beliefs, which are invoked by the different modalities of the task and its environment.

When using a computer application to perform knowledge work, people are faced with a composite task, which consists of a technical skill component, i.e., the use of the computerized tool, and a functional domain skill component that is needed to accomplish the knowledge task. Often, the two skill components evoke different efficacy beliefs and impose differences in behavior, which affect the overall outcome (Mackay \& Elam, 1992). Therefore, it was suggested that the measurement of self-efficacy at computer-mediated tasks should relate to both dimensions of the task: the execution of the knowledge assignment and the use of the computerized tool or application. Previous studies proposed a model of computer self-efficacy, which is composed of General Computer Self-Efficacy that spans across multiple computer applications, and task specific Computer Self-Efficacy, e.g., word-processing tasks (Marakas et al., 1998). Another study described a three-level model of self-efficacy in the area of online investment (Looney et al., 2006). The model defines the relations among the perceived efficacy in the technical component of the task, Computer Self-Efficacy in this case, efficacy at the functional domain component, Investment Self-Efficacy, and their combination, i.e., Online Investment Self-Efficacy.

Similarly, solving problems by means of prediction markets relies on two distinct skill sets. Traders need to form their opinions regarding the solution to the problems, and at the same time, they need to evaluate the market price signals with respect to their solution and decide whether to buy or sell stocks. These call for a definition of a dual facet self-efficacy construct that measures traders' efficacy beliefs at both perspectives of the task. Accordingly, the first research hypothesis is:

H1: Problem solving self-efficacy in prediction markets yields two distinct constructs that distinguish between efficacy beliefs at trading and problem-solving

\section{Online Collective Problem-Solving}

Collective intelligence platforms offer an online ecosystem that enables a group of people to collectively tackle a common intellectual challenge. Today, such platforms are common in the workplace, in learning environments, and in the public Internet sphere and are used to create knowledge repositories such as Wikipedia, software products in open-source projects (Github), make decisions (Loomio), or solve problems (Innocentive). Collective intelligence platforms combine the advantages of human cognition in handling intellectual, unstructured tasks with the benefits of the Internet as communication, aggregation and organization infrastructure, and are expected to alleviate some of the deficiencies of traditional group processes.

Collective intelligence platforms come in different flavors but they generally feature a low barrier of entry for a diverse and distributed population, they facilitate access to a large body of dispersed information, and they support diverse social and governance structures. A proposed classification places collective intelligence platforms on a continuum of social structure cohesiveness that ranges from heavyweight social structures, which maintain a community form of persistent structures and norms, to lightweight social structures, which are based on the independent operation of group members (Budhathoki \& Haythornthwaite, 2013). Open-source development projects, where programmers collaborate under different governance models, exemplify a highly cohesive community. GalaxyZoo (www.galaxyzoo.org), which is a platform that builds on a community of 
amateur astronomers to collectively create a morphological classification of galaxies, is an example of a loose group.

Social computing platforms are not to be confused with crowdsourcing platforms. In the latter, the complete task is handed out to a single entity, an individual or a team, and the platform does not mediate the social interaction. Kaggle (www.kaggle.com), as an example, facilitated a competition for a 3-dimensional algorithm that maps dark matter in the universe. While the activity may seem similar to that of GalaxyZoo, it does not involve an online collective process.

Prediction markets are lightweight collective-intelligence platforms that are used in the current research as a collective problem-solving platform.

\section{Prediction Markets}

Prediction markets use financial markets as an underlying mechanism to aggregate dispersed information, collect opinions of a large and distributed group of people, and predict future events (Wolfers \& Zitzewitz, 2004). In prediction markets, stocks are created so that their final cash value is tied to the outcome of a particular statement or question. It may refer to an event (e.g., will a nuclear arms disarmament treaty be signed with Iran before the end of the year?), to a parameter (e.g., how many tons of salt are there in the Dead Sea?) or to an opinion (e.g., will an increase of budget deficit decrease unemployment?). Traders express their opinions regarding the probability of the event or the value of the parameter by buying or selling a certain amount of stocks at the current price. The market mechanism updates the market price, which is interpreted as the collective opinion of all traders. Figure 1 displays a typical prediction market trading interface.

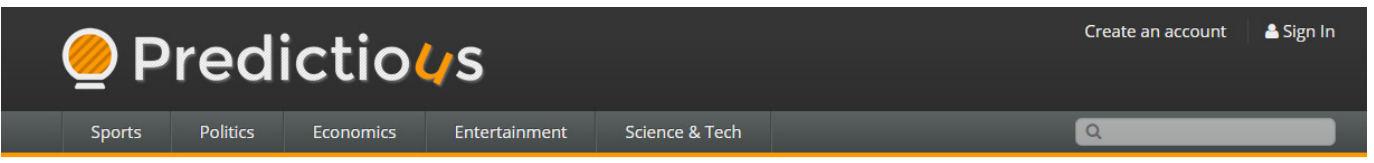

\section{Politics}
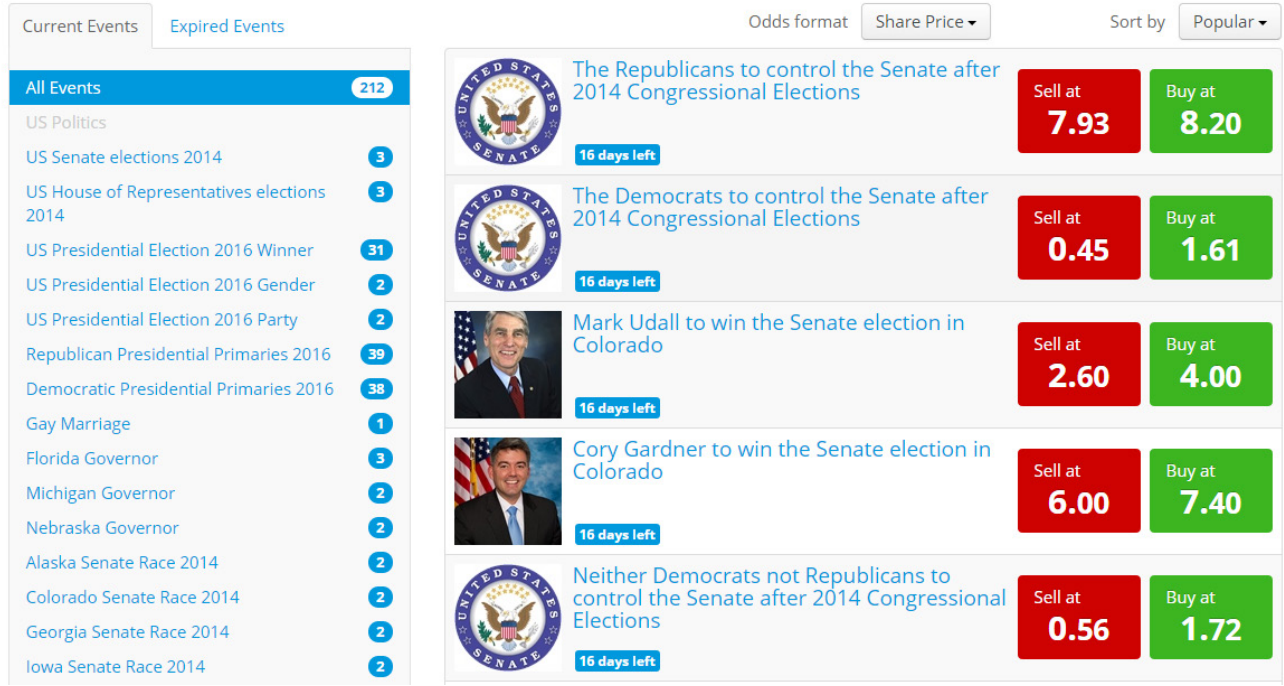

Figure 1: A typical prediction markets screen

Prediction markets can be configured to address the four types of cognitive tasks that were identified in the Stasser and Dietz-Uhler (2001) classification (Table 1), but they function better for intellective tasks (Slamka, Jank, \& Skiera, 2009). In the public Internet sphere, prediction markets address a variety of topics ranging from sports and entertainment to scientific innovation and 
politics. Due to anti-gambling regulations most markets use play-money and social incentives. The promise of prediction markets as a collective-intelligence platform lies in the corporate environment, the public sector, and civic debate (Cowgill et al., 2008; Polgreen, Nelson, \& Neumann, 2007; Slamka et al., 2009). There, they are used for innovation management, business forecasting, problem solving, and elicitation of knowledge and opinion (Geifman, Raban, \& Rafaeli, 2011).

The present study uses prediction markets to facilitate collective problem-solving. The aim of the second research hypothesis is to confirm their viability for the task:

H2: Prediction markets perform better than individuals at solving complex problems.

The accumulation of various market anomalies brought to the flourishing of the field of behavioral finance (Shiller, 2003). Prediction and financial market similarity leads to expect behavioral phenomena similar to those studied in the field of behavioral finance. Some studies in the field show that behavioral biases are evident in prediction markets (Cowgill et al., 2008; Gjerstad \& Hall, 2005), while others demonstrate market resilience to cognitive biases (Forsythe, Nelson, Neumann, \& Wright, 1992; Forsythe et al., 1999). The current research is interested in the influence of social-cognitive biases on the outcome of prediction markets. Specifically, we investigate the influence of self-efficacy on the outcome of prediction markets that perform as a collective problem-solving platform:

H3: Controlling for market-level knowledge, higher level of combined self-efficacy of traders in the market positively influences the collective solution

\section{Method}

Behavior of traders in prediction markets can be inferred from the market price or analyzed from transaction data. In the first case, studies analyze traders' behavior and biases by examining market price and its deviation from actual or from the expected price (Erikson \& Wlezien, 2008; Forsythe et al., 1999; Rhode \& Strumpf, 2006; Rothschild, 2009). To analyze the behavior of the individual trader, researchers must use transaction-level data and link it to traders' personal data. Public prediction markets do not allow access to trader-level personal data and studies that addressed individual behavior derived their data from markets that operated within organizations, where personal data on traders was accessible (Chen, Fine, \& Huberman, 2004; Cowgill et al., 2008; Spears, LaComb, Interrante, Barnett, \& Senturk-Dogonaksoy, 2009). To gain access to traders' personal characteristics and individual transactions, we designed an experiment and implemented prediction markets in a controlled laboratory setting that reflected a realistic environment. The markets were configured to collectively solve a complex problem, the Burglar problem, and the experiment procedure included a questionnaire by which the subjects reported their self-efficacy. A detailed description of the research instrument follows.

\section{The Burglar Problem}

A burglar broke into a house and filled his sacks with loot. Each sack weighs differently and contains different worth of goods. But alas!! When trying to leave the house, the burglar could not carry all the sacks with him, as the burden was too heavy.

Help the burglar choose the sacks he is able to carry while maximizing his profit

This seemingly naïve and simple riddle is a non-technical framing of the knapsack problem used in the fields of operational research and computer science to simulate a large family of combinatorial optimization problems. The formal presentation of the knapsack problem is: 


$$
\begin{aligned}
& \text { maximize } \sum_{j=1}^{n} p_{j} x_{j} \\
& \text { subject to } \sum_{j=1}^{n} w_{j} x_{j} \leq W, \quad x_{j} \in\{0,1\}
\end{aligned}
$$

Where $w_{j}$ and $p_{j}$ are item $j$ 's weight and profit respectively, $x_{j}$ is the selection flag for item $j$ (in/out), and $\mathrm{W}$ is the weight constraint. Table 2 illustrates a sample case of the problem (the player's goal is to find $\mathrm{X}$ ):

Table 2: Illustration of the knapsack problem

\begin{tabular}{|c|c|c|c|c|c|c|c|c|c|}
\hline $\mathbf{j}$ & 1 & 2 & 3 & 4 & 5 & 6 & 7 & 8 & 9 \\
\hline $\mathbf{p}$ & 37 & 72 & 106 & 32 & 45 & 71 & 23 & 44 & 85 \\
\hline $\mathbf{w}$ & 50 & 820 & 700 & 46 & 220 & 530 & 107 & 180 & 360 \\
\hline \hline $\mathbf{x}$ & 1 & 0 & 1 & 1 & 1 & 0 & 0 & 0 & 1 \\
\hline
\end{tabular}

The knapsack problem is computationally complex and solving it poses algorithmic challenges. In the general case, finding the items that form the optimal solution is computationally hard (NPcomplete). Heuristics may be applied to specific cases of the problem, but there is no one-fit-all heuristic. The problem does not always lend itself to a decomposition and synthesis strategy nor to an iterative strategy. Sometimes, the solver may need to drop the current course of solution and start the process anew.

Several reasons led to the selection of the Burglar problem for the current experiment. The Burglar problem is an intellective task, which has a demonstrable correct solution, but this solution is difficult to verify. As demonstrated by Meloso, Copic, and Bossaerts (2009), the complexity of the problem can be controlled by generating instances of the Burglar problem at various levels of complexity. The naïve framing of the problem, however, is easy to comprehend. Participants can quickly grasp the idea behind the problem and focus on its computational challenges. Its computational and context-neutral nature lowers the threat to validity of the experiment that may originate from unexpected interpretations of the scenario.

\section{The Prediction Market Platform}

We used a commercial prediction market platform (www.inklingmarkets.com), which was configured with the parameters of the Burglar problem. Each stock represented a sack, and its continuous price changes reflected the opinions of traders regarding the probability of the sack to be part of the solution. Ideally, at market closing, stocks of sacks that belonged to the solution would reach the price of 100 (local currency) and the price of others be nullified. In practice, however, a stock rarely reached 100 as market activity diminished before stock prices reached this point. A market correctly solved the problem when all stocks corresponding to sacks that constitute the solution were listed highest in price. We can envision the burglar examining the market prices and selecting sacks one by one from highest scoring to lowest scoring price until he can carry no more.

The user interface of the original platform was translated to Hebrew and slightly modified to facilitate better integration into the experiment flow. The new interface combined the information required during the experiment into two screens, the marketplace main screen (Figure 2) and the trading screen (Figure 3), which opened once the trader clicked on the "quick trade" button. The 
main trading screen presented the Burglar problem solution form and continuously displayed market-price changes and trader's holdings. This modification made it easier for the traders to reevaluate their own solution with respect to changing market-price signals. The platform recorded individual initial solutions to the Burglar problem, market price changes, and individual transactions for further analysis.

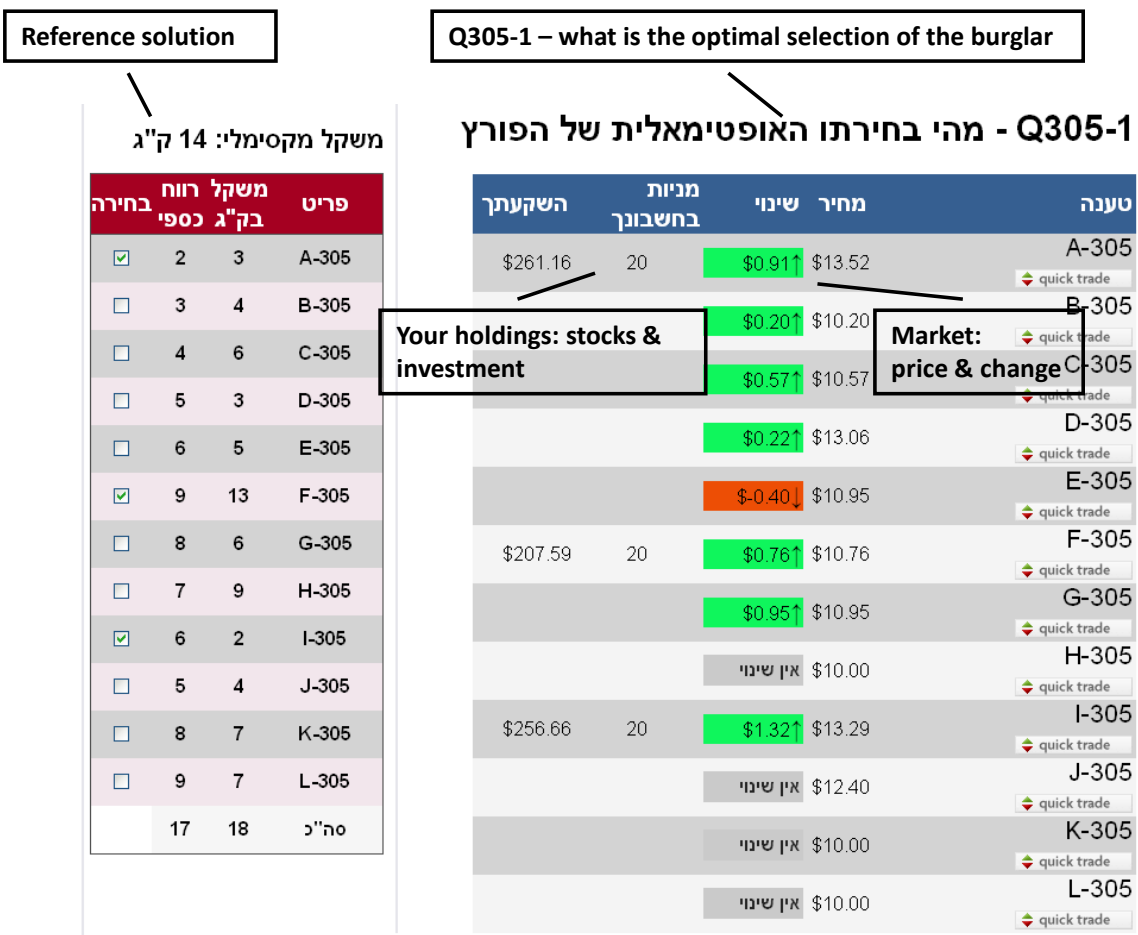

Figure 2: Marketplace screen (English translation added)

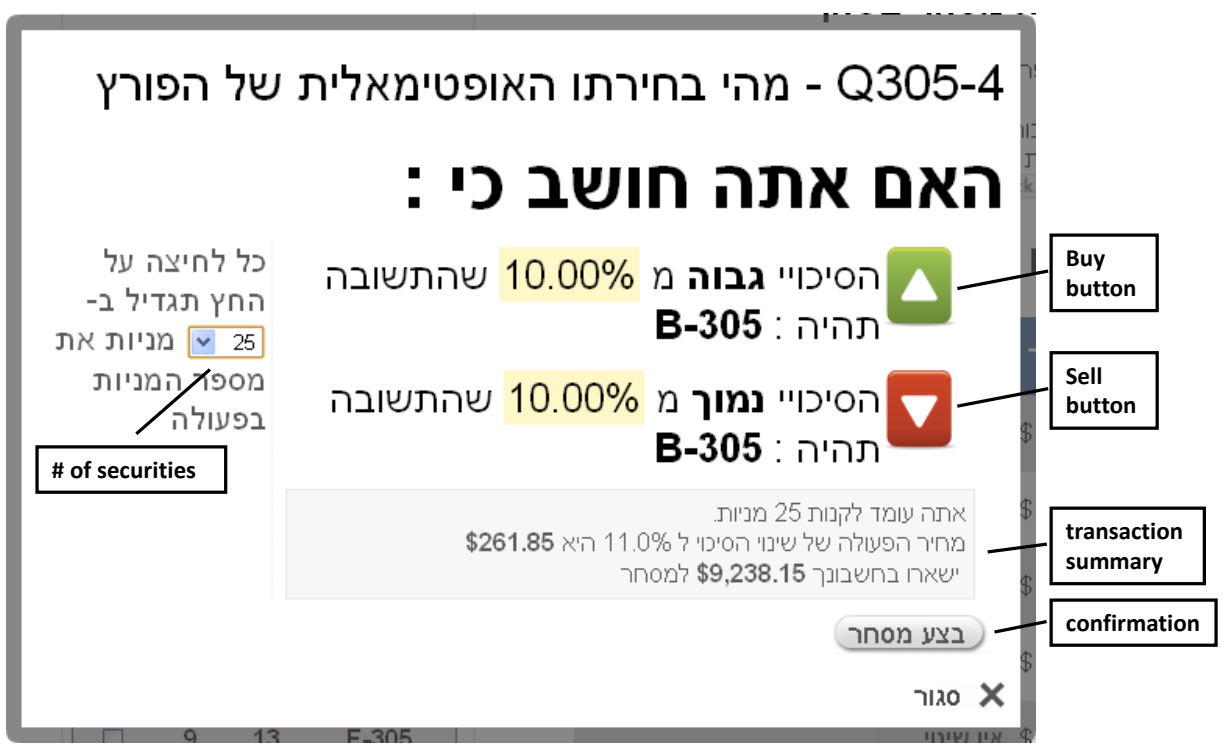

Figure 3: Trading screen (English translation added) 


\section{The Self-Efficacy Scale}

Solving problems by means of prediction markets comprises of two interleaved modalities. The trading activity requires that traders apply their skills and experience in the knowledge domain to form an opinion regarding the expected outcome of a future event or a complex problem. At the same time, by understanding how the current stock price relates to the opinion they formed on the topic of trade, they need to apply their trading skills to form a transaction that will optimize the use of their funds and maximize their profits. Both task modalities involve an element of uncertainty and ambiguity, which makes the judgment of perceived efficacy even more challenging.

To capture the complex nature of the task, the design of the self-efficacy scale included two types of items (Table 3). Four of the items, Prediction Markets Self-Efficacy (PMSE), related to selfefficacy at the trading. They were based on a scale developed by Looney et al. (2006) for measuring individual perceived efficacy at utilizing online technologies to accomplish investmentrelated tasks such as employing investment strategy or identifying good investments.

Self-efficacy at solving the Burglar problem, Burglar Problem Self-Efficacy (BPSE), was measured by two items. The design of these items followed Bandura's (1977) recommendation for measuring unidimensional tasks along the magnitude dimension, i.e., the difficulty level, and the dimension of self-efficacy strength. All items used a 6-point Likert scale following suggestions by other researchers (Gist \& Mitchell, 1992; Lee \& Bobko, 1994; Marakas et al., 1998).

Table 3: The self-efficacy scale

\begin{tabular}{|c|l|}
\hline Scale & \multicolumn{1}{|c|}{ Item } \\
\hline \multirow{4}{*}{ PMSE } & $\begin{array}{l}\text { I will succeed in applying a strategy that will maximize my profit when } \\
\text { trading in online prediction markets }\end{array}$ \\
\cline { 2 - 3 } & $\begin{array}{l}\text { I will succeed in identifying the correct solution while trading in online } \\
\text { prediction markets }\end{array}$ \\
\cline { 2 - 2 } & I will succeed in profiting from trading in online prediction markets \\
\cline { 2 - 2 } & $\begin{array}{l}\text { At market closing the value of my portfolio will be one of the top three in } \\
\text { the market }\end{array}$ \\
\hline \multirow{3}{*}{ BPSE } & $\begin{array}{l}\text { I will succeed in solving a medium level Burglar problem before the } \\
\text { opening of the market }\end{array}$ \\
\cline { 2 - 2 } & $\begin{array}{l}\text { I will succeed in solving a difficult Burglar problem before the opening of } \\
\text { the market }\end{array}$ \\
\hline
\end{tabular}

\section{The Experimental Procedure}

Participants in an experiment, which was framed as a competition, were asked to solve a Burglar problem and trade their solution in the marketplace. The experiment combined the questionnaire for eliciting participants' self-efficacy, a burglar problem module, and a marketplace for trading individual solutions into a streamlined flow. The experiment took place in a computer lab under controlled conditions. Each participant was assigned a dedicated computer and participants were not allowed to exchange information.

Participants reported their self-efficacy by filling a questionnaire, which included demographic questions and the 6 items of the self-efficacy scale. Upon completion, the participants were exposed to the main experiment scenario.

In the main scenario, participants had two minutes to solve an instance of the Burglar problem individually and form their own solution to the problem. When time expired, participants entered the marketplace to trade their solutions. During the trading process, participants could react to market-price signals, change their original solution, and revise their trading decisions. Trading time lasted 10-12 minutes, until market activity slowed to a halt. When the market closed, the 
final price of the stocks reflected the collective solution and the market was resolved according to the correct solution known to the experimenter. The account balance of the participants was updated based on their holdings and was displayed on a scoreboard. The highest ranking participant received a symbolic prize.

As most of the participants were not familiar with the Burglar problem or with prediction markets before the experiment, a training stage preceded the main part of the experiment. Training was divided into two steps. First, participants were asked to cope for five minutes with the Burglar problem only. This allowed participants sufficient time to understand the problem and experiment with different solving techniques. In the second step, they trained on the complete experiment scenario. It should be noted that the threat to internal validity of the experiment was reduced as the Burglar problem does not lend itself to a fit-all heuristic, which the participant can learn during the training sessions. Furthermore, after the training sessions the participants were not informed of the correct solutions to the Burglar problems and could not objectively evaluate their performance.

The variables that were derived from the questionnaire and system logs are described in Table 4. Trader level variables were used to calculate the market level variables, which were used in the analysis.

Table 4: Analysis variables

\begin{tabular}{|c|c|c|}
\hline Variable & Description & Source \\
\hline t_correct* & $\begin{array}{l}\text { A binary indication of the correctness of the trader's } \\
\text { individual solution }\end{array}$ & $\begin{array}{l}\text { Experiment } \\
\text { platform logs }\end{array}$ \\
\hline t_SE & $\begin{array}{l}\text { Trader's self-efficacy at the task. A } 6 \text { items, } 0-5 \\
\text { Likert-type scale }\end{array}$ & Self-report \\
\hline m_correct & $\begin{array}{l}\text { A binary indication of the correctness of the market } \\
\text { solution. True if highest price ranking stocks } \\
\text { represent all sacks that constitute a correct solution, } \\
\text { False otherwise. }\end{array}$ & $\begin{array}{l}\text { Market } \\
\text { platform logs }\end{array}$ \\
\hline m_accuracy & $\begin{array}{l}\text { Complement of the Root Mean Squared Error } \\
\text { (RMSE) of the final market price with respect to the } \\
\text { ideal price }\end{array}$ & $\begin{array}{l}\text { Market } \\
\text { platform logs }\end{array}$ \\
\hline m_knowledge & $\begin{array}{l}\text { Initial knowledge in the market. The proportion of } \\
\text { traders in the market who correctly identified the } \\
\text { solution before entering the market }\end{array}$ & $\begin{array}{l}\text { Experiment } \\
\text { platform log }\end{array}$ \\
\hline m_SE & Mean t_SE for traders in the market & Calculated \\
\hline
\end{tabular}

\section{Results}

632 Participants grouped in 47 markets participated in the experiments. The majority of the participants were undergraduate and graduate students, studying a variety of fields in different colleges and universities in Israel. In order to reach an older and more mature population a number of experiment sessions were conducted in a community setting, where the participants were invited to a social event that included a lecture on information markets followed by the experiment. Figure 4 describes the distribution of participants by age and gender. 


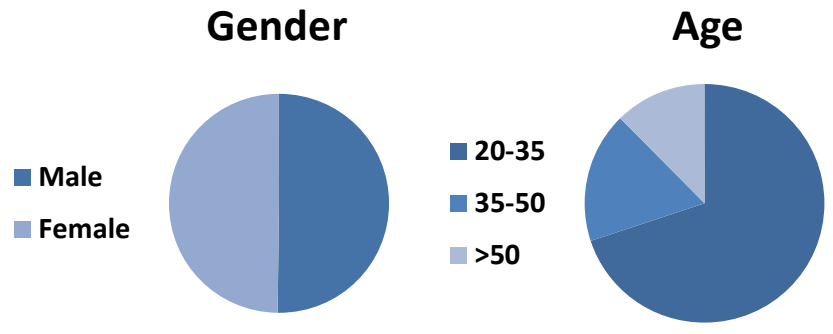

Figure 4: participants' age and gender

Individually, $21 \%$ of the traders succeeded in solving the Burglar problem before entering the market to trade. Collectively, $40 \%$ of the markets correctly identified the solution as measured by the m_correct flag (explained in Table 4). In 8 of the 47 markets no trader reached a correct solution before entering the market and none of these markets identified the correct solution. Out of the remaining 39 markets that included at least one solver, 19 markets identified the correct solution.

The trader self-efficacy scale ( $t$ SSE) demonstrated high reliability (Cronbach $\alpha=0.935$ ) and formed a unidimentional scale with all items loading above 0.85 on a single factor that explained $75 \%$ of the variance.

For each market a mean of traders' self-efficacy (t_SE) was calculated to form the aggregate measure of market self-efficacy (m_SE). The mean reliability within group, the rWG index (an estimate of the interrater agreement per market), was calculated to justify the use of $m \_S E$ as an aggregate measure (LeBreton \& Senter, 2008). In this case, the rWG index measured the variance of the self-efficacy of traders in a market with respect to the uniform distribution variance. Theoretically, its values may range from 0 - when market-level self-efficacy is completely random to 1 - when all traders in the market exhibit the same level of self-efficacy. The resulting mean value of 0.63 ( $n=47$ markets) was slightly below the recommended value of 0.7 (Cohen, Doveh, \& Eick, 2001).

The correlations presented in Table 5 demonstrate that market-level knowledge is positively correlated with market accuracy and so is market-level self-efficacy, but to a lesser extent. A positive correlation is also evident between knowledge and self-efficacy.

Table 5: Market-level correlations

\begin{tabular}{|l|c|c|c|}
\cline { 2 - 4 } \multicolumn{1}{c|}{} & $\begin{array}{c}\text { accurac } \\
\mathbf{y}\end{array}$ & knowledge & m_SE \\
\hline Knowledge & $.628^{* *}$ & & \\
\hline m_SE & $.329^{*}$ & $.339^{*}$ & \\
\hline Mean & -.611 & .22 & 2.53 \\
\hline SD & .135 & .162 & .403 \\
\hline p $<0.05, * * p<0.001$ & \multicolumn{3}{l}{}
\end{tabular}

Hierarchical regression was applied to determine the marginal contribution of market-level selfefficacy to the initial market-level knowledge in predicting the accuracy of the market.

Knowledge was introduced first to the model, followed by $\mathrm{m}_{-} \mathrm{SE}$. With all variables in the equation, the model was statistically significant $(F(2,44)=15.27, \bar{p}<0.001)$ and the adjusted $R^{2}$ indicated that the model predicted $38 \%$ of variance in market accuracy. It is, however, evident from Table 6 that market-level self-efficacy did not contribute to the model. 
Table 6: Market accuracy hierarchical regression

\begin{tabular}{|l||c|c|c|c|}
\hline Step & Variable & $\begin{array}{c}\mathbf{R}^{2} \\
\text { change }\end{array}$ & F change & $\boldsymbol{\beta}$ \\
\hline $\mathbf{1}$ & knowledge & .394 & 29.317 & $.584 * *$ \\
\hline $\mathbf{2}$ & m_SE & .015 & 1.132 & .131 \\
\hline$* * P<0.001$
\end{tabular}

\section{Discussion}

Crowdsourcing for solutions to scientific, business and other problems has become common and is supported by commercial platforms, e.g., Innocentive (www.innocentive.com) and NineSigma (www.ninesigma.com), as well as non-commercial platforms such as Nasa Tournament Lab (http://www.nasa.gov/coeci/ntl) and Challenge.gov. By providing access to independent and diverse individual problem solvers, crowdsourcing platforms facilitate original solutions to complex problems. These platforms, however, support processes that are sponsored by an organization and the "crowd" is directed and managed by these organizations. They do not entail collaboration, coordination, or aggregation mechanisms that facilitate collective problem solving (Brabham, 2012). The current research studied the process of collective problem-solving by collectiveintelligence platforms, prediction markets, which facilitate online collaboration among individual problem-solvers through online interactivity and lie on the lightweight end of the social cohesion spectrum of social computing platforms (Budhathoki \& Haythornthwaite, 2013). The Discussion will first elaborate on the interplay between the technical and functional perspectives of selfefficacy at computer mediated problem-solving and will then explain how prior knowledge and self-efficacy influence collective solutions in online collaborative environments.

Trading individual solutions on prediction markets involves two distinct yet interwoven activities. Traders process information and knowledge to form their own solutions to the problem and at the same time, they need to evaluate market signals conveyed through the market price, and decide whether to take an action in the market or revise their solution. If they decide to trade, they need to transform their judgment into a buying or selling transaction in a manner that will optimize the use of their funds and maximize their profits. The complexity of the task and the operational environment called for two self-efficacy measures (Table 3): PMSE measured self-efficacy at trading in prediction markets, and BPSE measured self-efficacy at solving the burglar problem. Hypothesis H1, which assumed that the measurement of self-efficacy at trading individual solutions on prediction markets will yield two distinct constructs, rested on previous studies (Compeau \& Higgins, 1995; Looney, Valacich, \& Akbulut, 2004; Marakas et al., 1998).

Factor analysis of PMSE and BPSE rendered a unidimensional construct, implying that participants did not differentiate between their efficacy at solving the Burglar problems and at trading on prediction markets, as a result $\mathrm{H} 1$ is rejected. We suggest three possible explanations. The first claims that since the two tasks are interleaved, the relation between their related efficacy beliefs is not straightforward. The second explanation looks into aspects of experience and familiarity with the task and the third suggests that the framing of the task has an important role in forming efficacy beliefs. In the following we unpack these explanations.

Looney et al. (2006) distinguish between activities that involve different skills, each confined to a discrete domain, and activities that employ a blend of skills from two or more domains. In their study of online financial trading they viewed computer self-efficacy and investment self-efficacy as two distinct components, but combined online trading self-efficacy and perceived efficacy at making the investment decisions into single construct that consisted of items in the form of: "I can use an online investment web-site to choose investments wisely". It is suggested that as the 
use of computer is more common in daily activities, especially for the millennial generation, selfefficacy at both task components is blended into a single perception and individuals do not distinguish between their technical and functional efficacies. This may call for a revisit of earlier studies in the area of computer self-efficacy.

The dynamics of and interplay between the technical and functional components of composite tasks, from the perspectives of performance and self-efficacy, mature over time as experience builds up (Agarwal, Sambamurthy, \& Stair, 2000; Mackay \& Elam, 1992). Mackay and Elam (1992) found that expertise in the computerized tool dominated the performance in the problemsolving task and that functional knowledge was not enough to overcome lack of technical proficiency. Agarwal et al. (2000) demonstrated that while computing self-efficacy has a significant effect on the perceived efficacy in training of the first computer application, its effect diminishes at the training of the next application. As most participants were not familiar with the Burglar problem or trading on prediction markets, we may assume that self-efficacy at trading, i.e., the technical skill, dominated the perceived efficacy at solving the Burglar problem and was the one that was actually measured. Additional research, which would manipulate the maturity level of the two self-efficacy components, can provide further insights into the maturation process of selfefficacy in composite tasks.

Prior studies defined measurement models for self-efficacy at composite tasks by focusing on the skill-sets required to accomplish the task (Agarwal et al., 2000; Compeau \& Higgins, 1995;

Looney et al., 2006; Marakas et al., 1998). The lack of discrimination between the perceived efficacies at the two skill components may suggest that cognitive processes that build efficacy beliefs focus on the outcome of the activity rather than on the resources that are required to accomplish it. The participants in our experiment were advised that as individuals, success would be measured by the value of their account at market closing. They must have been aware that success in solving the problem would improve the chances of personal success; however, the measurement of their personal success was linked to the market and not to the problem. We offer here a new perspective to understanding the roots of efficacy beliefs and suggest that when individuals judge their efficacy, they do not distinguish between the skill-sets that they apply; instead they focus on the stated performance measure. This hypothesis, however, requires further research.

Another objective of this research was to evaluate the effectiveness of prediction markets as a collective problem-solving platform and their resilience to behavioral biases. Benchmarking the effectiveness of group processes dates back to early research in the field. Scholars compared the percentage of individuals who correctly solved a problem to the percentage of groups who solved the same problem and demonstrated that groups were more effective in solving an intellective problem (Shaw, 1932). Later researchers claimed that this averaging method does not reflect the potential of the collective process and that the effectiveness of the group should be evaluated with respect to the effectiveness of the best of its members, especially for problems that cannot be decomposed into discrete components (Steiner, 1972).

The current research demonstrated that while $21 \%$ of the traders correctly solved the problem before entering the market, $40 \%$ of the markets reached the correct solution when measured by the $\mathrm{m}$-correct flag. This means that the market mechanism significantly amplified the ability of the average individual to solve problems. However, when looking at market performance through the "best member" performance lens, we see that markets with no individual solver did not identify the correct solution, and only $50 \%$ of the markets that included at least one correct solver arrived at the correct solution. Does this mean that prediction markets are not effective platforms for collective problem-solving? We claim that the effectiveness of social computing platforms in solving problems should be measured by the averaging method and not by the best member method. 
When an expert or knowledgeable person in a certain domain is available, there is no need to revert to methods of collective problem solving. However, it is often the case that finding the best problem-solver is like finding a needle in a haystack. Crowdsourcing platforms like Kaggle and Innocentive offer prizes and rewards in order to draw the best problem-solvers out of the "crowd". Social computing platforms take a different approach. They facilitate access to a large diverse pool of potential problem solvers and information resources with no guarantee that the best problem-solver is present in the group. At the same time, they provide an infrastructure such as an environment of social interaction, community building and aggregation methods, with the hope that the combined effort will produce a good collective solution. As it is not guaranteed that the expert participates in the collective effort, it is suggested that the performance of social computing platform be measured by comparing the probability of the group coming up with the correct collective solution to that of the average individual. Based on this consideration we suggest that prediction markets are an effective problem solving platform, confirming hypothesis H2. Furthermore, this research claims that by adding an aggregation mechanism to crowdsourcing platforms, the process of problem-solving can significantly improve.

In line with the efficient markets theory (Fama, 1970), the analysis of the data exhibited a high positive correlation between the performance of the market, measured by its accuracy, and the knowledge that traders introduced to the market $(\mathrm{r}=.628, \mathrm{p}<0.001)$. The aim of this research was to investigate the effect of self-efficacy, a personal social-cognitive disposition, on the collective solution. While market-level self-efficacy positively correlated with the accuracy of the market $(\mathrm{r}=.339, \mathrm{p}<0.05)$, a hierarchical regression model demonstrated that it did not contribute to the market accuracy beyond the prior knowledge of the traders. By rejecting hypothesis H3, this research supports the position of the neoclassical economists and demonstrates that the market mechanism is robust and prediction markets are resilient to self-efficacy biases.

This research relies on two theories that touch on social influence. Self-efficacy is a socialcognitive theory that suggests that personal efficacy beliefs are mainly affected by the experience of personal mastery, yet affective and social factors, such as vicarious experience and verbal persuasion, also play a role in the formation of the perception of self-efficacy. Theories of normative and informational influence explain social influence in group processes. Normative influence theory focuses on the position of the individual in the group, emphasizing motives such as seeking social rewards and interpersonal relations. Informational influence theory emphasizes the task dimension and the drive of the individual to reach an accurate outcome.

In prediction markets, the potential of normative influence is low as persistent social structures are not created. Informational influence, however, may be present as the traders derive cues about the opinions of other traders from the changing market price and the amount of stocks traded (Guarnaschelli, Kwasnica, \& Plott, 2003). These cues can be interpreted as vicarious experience, which play a role in self-efficacy perception. The other social factor that affects self-efficacy, verbal persuasion, does not play a role in this case as traders in real-life are anonymous and in this experiment were asked not to interact with each other. Kaplan and Miller (1987) show that informational influences are predominant in groups that deal with intellective issues; it was therefore hypothesized that self-efficacy perception of the individual will affect the collective outcome. In the case of prediction markets, this hypothesis was rejected.

It would be interesting to investigate the influence of self-efficacy in collaborative problemsolving platforms that exhibit more cohesive social structures. Two potential candidates for such research are Polymath (Ball, 2014; Cranshaw \& Kittur, 2011) and MathOverflow (Tausczik, Kittur, \& Kraut, 2014). The first addresses complex mathematical problems and incorporates an established governance structure. The second is geared towards smaller mathematical problems and engages a broad community of mathematicians, who are rewarded with kudos and badges. 


\section{Conclusion}

The objective of this research was to understand the manifestation of individual self-efficacy in collective-intelligence processes and specifically, its effect on the collective outcome of prediction markets that function as a problem-solving platform. To this end, 632 participants traded in 47 markets possible solutions to a complex, structured problem, the Burglar problem. Findings show that prediction markets form an effective instrument for solving complex structured prob-

lems. On average, the collective solution of the market was better than the individual solution as $40 \%$ of the markets produced a correct solution to the problem vs. $21 \%$ of the individuals who succeeded in solving the problem. This confirms hypothesis $\mathrm{H} 2$, which states that prediction markets perform better than individuals at solving complex problems. Hypothesis H3, which states that controlling for market-level knowledge, higher level of combined self-efficacy of traders in the market positively influences the collective solution, was rejected. Individual self-efficacy had no contribution to the quality of the collective outcome beyond the knowledge that participants introduce into the prediction market. These findings indicate that (a) the aggregation mechanism of prediction markets, the market's price function, is efficient and is resilient to biases that may arise from individual perceived efficacy and (b) the market aggregates knowledge rather than affective influences.

Another important finding of the research relates to the measurement of self-efficacy at computer-mediated knowledge tasks, specifically those performed in a collective environment. It stems from the rejection of hypothesis H1, which states that problem solving self-efficacy in prediction markets yields two distinct constructs that distinguish between efficacy beliefs at trading and problem-solving. The research demonstrated that although the task of trading in prediction markets involves two distinct skill-sets, one that relates to the knowledge component of the task and one to its technical aspect, individuals perceive their activity in the task as holistic. From the perspective of their self-efficacy, the participants did not differentiate between the two components. This finding contests earlier models of self-efficacy in the area of computer-mediated activities that differentiate between computer proficiency and the knowledge skills. One of the reasons may be that computers are no longer regarded by us as a tool but rather as a transparent extension of our cognitive faculties.

The contribution of this research is two-fold. It enhances self-efficacy theory with the understanding of self-efficacy at tasks that combine technical and functional components, tasks that are common in today's daily activities. Furthermore, it contributes an additional perspective to the effectiveness of prediction markets as collective decision-making and problem-solving mechanism. The findings substantiated their position as a collective platform within the plethora of organizational social computing platforms.

The research focused on collective problem-solving using prediction markets. It addressed only one of the four categories of cognitive tasks that can benefit from social computing environments, problem-solving, and studied it on a platform that entails limited social interaction. Further research in needed to confirm that the findings of the current research hold for tasks of choice, judgment, and estimation that are performed in cooperative computer mediated platforms with more cohesive social structures.

\section{References}

Agarwal, R., Sambamurthy, V., \& Stair, R. M. (2000). Research report: The evolving relationship between general and specific computer self-efficacy-An empirical assessment. Information Systems Research, 11(4), 418-430.

Ball, P. (2014). Crowd-sourcing: Strength in numbers. Nature, 506(7489), 422-423. 
Bandura, A. (1977). Self-efficacy: Toward a unifying theory of behavioral change. Psychological Review, 84(2), 191-215.

Bandura, A. (1986). Social foundations of thought and action: A social cognitive theory. Prentice-Hall, Inc.

Bandura, A. (1997). Self-efficacy: The exercise of control. Macmillan.

Bandura, A. (2012). On the functional properties of perceived self-efficacy revisited. Journal of Management, 38(1), 9-44.

Bandura, A., \& Schunk, D. H. (1981). Cultivating competence, self-efficacy, and intrinsic interest through proximal self-motivation. Journal of Personality and Social Psychology, 41(3), 586.

Bandura, A., \& Wood, R. (1989). Effect of perceived controllability and performance standards on selfregulation of complex decision making. Journal of Personality and Social Psychology, 56(5), 805.

Bouffard-Bouchard, T. (1990). Influence of self-efficacy on performance in a cognitive task. The Journal of Social Psychology, 130(3), 353-363.

Bouffard-Bouchard, T., Parent, S., \& Larivee, S. (1991). Influence of self-efficacy on self-regulation and performance among junior and senior high-school age students. International Journal of Behavioral Development, 14(2), 153-164.

Brabham, D. C. (2012). Crowdourcing: A model for leveraging online communities. In A. Delwiche, \& J. J. Henderson (Eds.), The participatory cultures handbook (1st ed., pp. 120) Routledge.

Brown, R. (2000). Group processes: Dynamics within and between groups Blackwell Publishing.

Budhathoki, N. R., \& Haythornthwaite, C. (2013). Motivation for open collaboration: Crowd and community models and the case of OpenStreetMap. American Behavioral Scientist, 57(5), 548.

Burnstein, E., \& Vinokur, A. (1977). Persuasive argumentation and social comparison as determinants of attitude polarization. Journal of Experimental Social Psychology, 13(4), 315-332.

Chemers, M. M., Hu, L., \& Garcia, B. F. (2001). Academic self-efficacy and first year college student performance and adjustment. Journal of Educational Psychology, 93(1), 55.

Chen, K. Y., Fine, L. R., \& Huberman, B. A. (2004). Eliminating public knowledge biases in informationaggregation mechanisms. Management Science, 50(7), 983-994.

Cohen, A., Doveh, E., \& Eick, U. (2001). Statistical properties of the rWG (J) index of agreement. Psychological Methods; Psychological Methods, 6(3), 297.

Compeau, D. R., \& Higgins, C. A. (1995). Computer self-efficacy: Development of a measure and initial test. MIS Quarterly, 19(2), 189-211.

Condiotte, M. M., \& Lichtenstein, E. (1981). Self-efficacy and relapse in smoking cessation programs. Journal of Consulting and Clinical Psychology, 49(5), 648.

Cowgill, B., Wolfers, J., \& Zitzewitz, E. (2008). Using prediction markets to track information flows: Evidence from google. Dartmouth College. Retrieved from http://www.bocowgill.com/GooglePredictionMarketPaper.pdf

Cranshaw, J., \& Kittur, A. (2011). The polymath project: Lessons from a successful online collaboration in mathematics. Proceedings of the SIGCHI Conference on Human Factors in Computing Systems, pp. 1865-1874.

Erikson, R. S., \& Wlezien, C. (2008). Are political markets really superior to polls as election predictors? Public Opinion Quarterly, 72(2), 190-215.

Fama, E. F. (1970). Efficient capital markets. Journal of Finance, 25(2), 383-421.

Forsythe, R., Nelson, F., Neumann, G. R., \& Wright, J. (1992). Anatomy of an experimental political stock market. The American Economic Review, 82(5), 1142-1161. 
Forsythe, R., Rietz, T. A., \& Ross, T. W. (1999). Wishes, expectations and actions: A survey on price formation in election stock markets. Journal of Economic Behavior and Organization, 39(1), 83-110.

Geifman, D., Raban, D. R., \& Rafaeli, S. (2011). P-MART: Towards a classification of online prediction markets. First Monday, 16(7). Available at http://pear.accc.uic.edu/ojs/index.php/fm/article/view/3203/3019

Gigone, D., \& Hastie, R. (1993). The common knowledge effect: Information sharing and group judgment. Journal of Personality and Social Psychology, 65(5), 959-974.

Gist, M. E., \& Mitchell, T. R. (1992). Self-efficacy: A theoretical analysis of its determinants and malleability. The Academy of Management Review, 17(2), 183-211.

Gjerstad, S., \& Hall, M. C. (2005). Risk aversion, beliefs, and prediction market equilibrium. Economic Science Laboratory, University of Arizona.

Guarnaschelli, S., Kwasnica, A. M., \& Plott, C. R. (2003). Information aggregation in double auctions: Rational expectations and the winner's curse. Information Systems Frontiers, 5(1), 63-77.

Isenberg, D. J. (1986). Group polarization: A critical review and meta-analysis. Journal of Personality and Social Psychology, 50(6), 1141-1151.

Janis, I. L. (1982). Groupthink: Psychological studies of policy decisions and fiascoes. Boston: Houghton Mifflin.

Janssen, D. (1997). Instructional design models for well-structured and ill-structured problem solving learning outcomes. Educational Technology Research \& Development, 45(1), 45-94.

Kaplan, M. F., \& Miller, C. E. (1987). Group decision making and normative versus informational influence: Effects of type of issue and assigned decision rule. Journal of Personality and Social Psychology, 53(2), 306.

Krueger, N., \& Dickson, P. R. (1994). How believing in ourselves increases risk taking: Perceived selfefficacy and opportunity recognition. Decision Sciences, 25(3), 385-400.

Laughlin, P. R., \& Ellis, A. L. (1986). Demonstrability and social combination processes on mathematical intellective tasks. Journal of Experimental Social Psychology, 22(3), 177-189.

LeBreton, J. M., \& Senter, J. L. (2008). Answers to 20 questions about interrater reliability and interrater agreement. Organizational Research Methods, 11(4), 815-852.

Lee, C., \& Bobko, P. (1994). Self-efficacy beliefs: Comparison of five measures. Journal of Applied Psychology, 79(3), 364-369.

Locke, E. A., Frederick, E., Lee, C., \& Bobko, P. (1984). Effect of self-efficacy, goals, and task strategies on task performance. Journal of Applied Psychology, 69(2), 241.

Looney, C. A., Valacich, J. S., \& Akbulut, A. Y. (2004). Online investment self-efficacy: Development and initial test of an instrument to assess perceived online investing abilities. System Sciences, 2004. Proceedings of the 37th Annual Hawaii International Conference on, p. 9.

Looney, C. A., Valacich, J. S., Todd, P. A., \& Morris, M. G. (2006). Paradoxes of online investing: Testing the influence of technology on user expectancies. Decision Sciences, 37(2), 205-246.

Mackay, J. M., \& Elam, J. J. (1992). A comparative study of how experts and novices use a decision aid to solve problems in complex knowledge domains. Information Systems Research, 3(2), 150-172.

Marakas, G. M., Yi, M. Y., \& Johnson, R. D. (1998). The multilevel and multifaceted character of computer self-efficacy: Toward clarification of the construct and an integrative framework for research. Information Systems Research, 9(2), 126.

Meloso, D., Copic, J., \& Bossaerts, P. (2009). Promoting intellectual discovery: Patents versus markets. Science, 323(5919), 1335.

Newell, A., \& Simon, H. A. (1972). Human problem solving. Englewood Cliffs, NJ: Prentice-Hall. 
O'Leary, A. (1985). Self-efficacy and health. Behaviour Research and Therapy, 23(4), 437-451.

Pajares, F., \& Kranzler, J. (1995). Self-efficacy beliefs and general mental ability in mathematical problemsolving. Contemporary Educational Psychology, 20(4), 426-443.

Parker, P. D., Marsh, H. W., Ciarrochi, J., Marshall, S., \& Abduljabbar, A. S. (2014). Juxtaposing math self-efficacy and self-concept as predictors of long-term achievement outcomes. Educational Psychology, 34(1), 29-48.

Payne, J. W. (1982). Contingent decision behavior. Psychological Bulletin, 92(2), 382.

Polgreen, P. M., Nelson, F. D., \& Neumann, G. R. (2007). Use of prediction markets to forecast infectious disease activity. Clinical Infectious Diseases, 44(2), 272-279.

Rhode, P. W., \& Strumpf, K. S. (2006). Manipulating political stock markets: A field experiment and a century of observational data. University of North Carolina. Available at https://www.unc.edu/ cigar/papers/ManipIHT_June2008\%28KS\%29.pdf

Rothschild, D. (2009). Forecasting elections comparing prediction markets, polls, and their biases. Public Opinion Quarterly, 73(5), 895.

Shaw, M. E. (1932). A comparison of individuals and small groups in the rational solution of complex problems. American Journal of Psychology, 44(3), 491-504.

Shiller, R. J. (2003). From efficient markets theory to behavioral finance. Journal of Economic Perspectives, 17(1), 83-104.

Simon, H. A. (1969). The sciences of the artificial.

Slamka, C., Jank, W., \& Skiera, B. (2009). Second-generation prediction markets for information aggregation: A comparison of payoff mechanisms. Journal of Forecasting, 31(6), 469-489.

Spears, B., LaComb, C., Interrante, J., Barnett, J., \& Senturk-Dogonaksoy, D. (2009). Examining trader behavior in idea markets: An implementation of GE's imagination markets. The Journal of Prediction Markets, 3(1), 17-39.

Stasser, G., \& Dietz-Uhler, B. (2001). Collective choice, judgment, and problem solving. In M. A. Hogg, \& S. R. Tindale (Eds.), Blackwell handbook of social psychology: Group processes (pp. 31-55). Oxford, England: Blackwell.

Stasser, G., \& Titus, W. (1985). Pooling of unshared information in group decision making: Biased information sampling during discussion. Journal of Personality and Social Psychology, 48(6), 1467-1478.

Steiner, I. (1972). Group process and productivity. New York.

Tausczik, Y. R., Kittur, A., \& Kraut, R. E. (2014). Collaborative problem solving: A study of mathoverflow. Proceedings of the 17th ACM Conference on Computer Supported Cooperative Work \& Social Computing, pp. 355-367.

Wang, Y., \& Chiew, V. (2010). On the cognitive process of human problem solving. Cognitive Systems Research, 11(1), 81-92.

Wolfers, J., \& Zitzewitz, E. (2004). Prediction markets. Journal of Economic Perspectives, 18(2), 107-126. 


\section{Biographies}

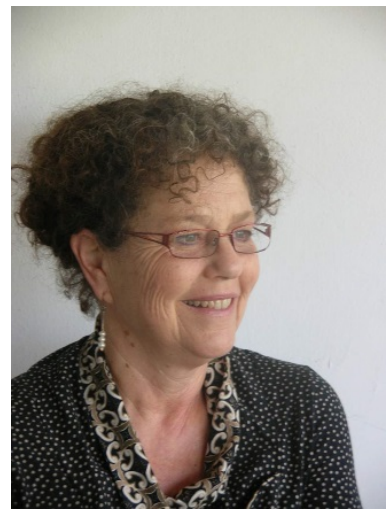

Dorit Geifman is a research associate at the Center for Internet Research (infosoc.haifa.ac.il) and teaches information economics at the Department of Information and Knowledge Management at the University of Haifa. Her research interest lies in social-economic perspectives of social-computing systems and specifically in the implications of participants' behavior on the performance of such platforms. Dorit has published in refereed IS journals and presented her research in several international conferences in the field.

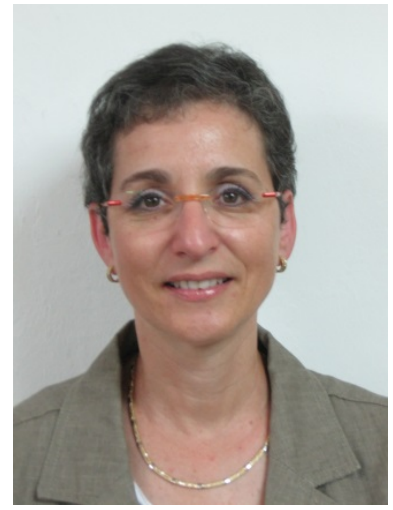

Daphne R. Raban is a Senior Lecturer at the Faculty of Management, University of Haifa and Head of the Department for Information and Knowledge Management. She is active in the Center for Internet Research (infosoc.haifa.ac.il) and in LINKS (links.org.il). Her broad area of research interest is the value of information including topics such as information markets, economics of information goods, information/knowledge sharing, the interplay between social and economic incentives, and games and simulations. Daphne published in top-tier journals such as JAIS, EJIS, JASIST, Scientometrics and others. 